\title{
KONSEP PERENCANAAN FESTIVAL MUSIK UNTUK ANAK-ANAK DI SMA TERUNA MUDA CIBUBUR
}

\author{
Nadya Priscilla Nauli ${ }^{1}$ \\ London School of Public Relations Communication \& Business Institute \\ Email: priscill.nadya@gmail.com
}

\begin{abstract}
ABSTRAK
Konsep perencanaan karya non skripsi ini bertujuan untuk mengetahui bagaimana perkembangan dunia seni musik khususnya di dalam pendidikan sekolah yang mayoritas anak-anaknya menyukai festival seni musik di SMA Teruna Muda Cibubur. Hal ini dilandasi oleh ketertarikan pembuat karya pada seni musik dan perkembangan festival musik sekolah yang jarang di ketahui oleh banyak orang sehingga belum banyak orang yang menyadari bahwa sudah banyak anak-anak sekolah yang menyukai seni dalam bidang musik khususnya festival, sehingga pembuat karya mengangkat perencanaan rancangan karya non skripsi untuk mewadahi anak-anak khususnya di SMA Teruna Muda Cibubur untuk menyalurkan bakat dan ketertarikan mereka terhadap dunia musik. Pembuat karya bertujuan untuk memberikan kesadaran kepada khalayak umum agar dapat menyadari atau memberikan simpati yang lebih untuk anak-anak sekolah menengah atas yang mempunyai bakat non akademik dengan kemampuan yang dimiliki namun belum sempat tersampaikan. Rancangan konsep karya ini menggunakan teori event management, perancang karya mengartikan bahwa event merupakan sebuah kegiatan yang bisa berwujud atraksi hiburan, tradisi, budaya, olahraga, dan lain sebagainya yang dilakukan dalam kurun waktu tertentu dengan mendatangkan orang-orang ke suatu tempat agar mereka memperoleh informasi atau pengalaman penting serta tujuan lain yang diharapkan oleh perancang. Pembuat karya membuat sebuah konsep perencanaan festival musik di SMA Teruna Muda Cibubur, untuk menampilkan suatu karya seni guna untuk mengapresiasikan bakat dari anak-anak sekolah SMA Teruna Muda Cibubur, dan dikemas menjadi sebuah event festival musik. Rancangan karya ini untuk membuat festival musik di SMA Teruna Muda Cibubur. Pembuat karya akan menjadikan ini misi sebagai meningkatkan rasa seni dan menjunjung kreativitas anak-anak disekolah SMA Teruna Muda Cibubur.
\end{abstract}

Kata Kunci: Komunikasi, Seni, Event Management

\section{THE CONCEPT OF PLANNING A MUSIC FESTIVAL FOR CHILDREN IN JUNIOR HIGH SCHOOL CIBUBUR}

\begin{abstract}
The concept of non-thesis work planning aims find out how the development of the world of music art, especially in school education, where the majority of the students at Teruna Muda Cibubur High School love music art festivals. This is based on the interest of the creators of music, arts and the development of school music festivals which are rarely known by many people, so not many people realize that there are students in many school who like arts in music, especially festivals, so the creators raise design plans non-thesis works to accommodate the students especially at Teruna Muda Cibubur High School to channel their talents and interests to the world in music. The creator of the work aims to provide awareness to the general public so that they can realize or give more sympathy to high school students who have non-academic talents with abilities that they have but don't have enough time to convey. The design of this work concept uses the event management theory, the work designer means that the event is an activity that can take the form of attractions of entertainment, tradition, culture, sports, etc. That are carried out in a certain period of time by bringing people to some places so they can get information or important experience and other objectives expected by the designer. The creator made a concept to planning Teruna Muda Cibubur High School, to present a a music festival at work of arts to appreciate the talents of students of Teruna Muda Cibubur High School, and packed into a music festival event. The design of this work is to make a music festival at Teruna Muda Cibubur High School. The creator of the work will make this as a mission to increase the sense of arts and uphold the creativity of students at Teruna Muda Cibubur High School.
\end{abstract}

Keywords: Communication, Arts, Event Management. 
Korespondensi: Nadya Priscilla Nauli. LSPR Communication \& Business. Bumi Mutiara Blok JF 12 No.6, Kab Bogor, Jawa Barat, 16969. No.Hp/WhatsApp081806173657. Priscill.nadya@gmail.com

\section{PENDAHULUAN}

Seni adalah suatu ekspresi perasaan manusia yang memiliki unsur keindahan di dalamnya dan diungkapkan melalui suatu media yang sifatnya nyata, baik itu dalam bentuk nada, rupa, gerak, dan syair, serta dapat dirasakan oleh panca indera manusia. Pertunjukkan adalah karya seni yang melibatkan aksi individu atau kelompok di tempat dan waktu tertentu. Seni pertunjukkan merupakan salah satu bentuk seni yang kompleks karena pada seni pertunjukkan tidak hanya melibatkan satu 1 jenis namun komponennya melibatkan berbagai jenis karya seni. Seperti pada pertunjukkan teater. Seni yang ditampilkan bukan hanya seni peran, melainkan gabungan antara seni peran,

musik dan seni rias untuk kostum dan make up yang dikenakan para pemain. Seni pertunjukkan tidak dapat berdiri sendiri maka dari itu seni ini disebut sebagai bentuk seni yang kompleks. (Manroe, 2018, para. 1)

Indonesia kaya dengan seni dan tradisi pertunjukkan yang beraneka ragam. Salah satu seni pertunjukkan yang biasanya dilakukan dimana saja seperti di tempat umum, di sekolah, adalah konser atau festival musik. Seni pertunjukkan atau performing arts itu sendiri adalah salah satu hal untuk menyampaikan pesan melalui sebuah atau serangkaian karya seni. (Fadillah, 2019, para. 1)

Salah satu bentuk seni pertunjukkan yang cukup banyak digemari masyarakat adalah musik. Musik adalah suatu hasil karya seni berupa bunyi dalam bentuk lagu atau komposisi yang mengungkapkan pikiran dan perasaan penciptanya melalui unsur-unsur pokok musik yaitu irama, melodi, harmoni, serta ekspresi sebagai suatu kesatuan (Rusyanti, 2013). Musik ada dalam kehidupan sehari-hari kita, saat sedang santai, mengungkapkan perasaan, dan menghibur diri, semua dapat disalurkan melalui musik. Bahkan, banyak orang menyampaikan pesan perdamaian melalui musik itu sendiri (Augustin, 2015).

Musik memiliki jenis atau genre yang beragam Rock, Pop, Metal, Classic, Funk, Electronic, Country, Blues, Reggae, Metal, Disco, Hip Hop, R\&B, Rap dan Jazz (Ilham, 2013). Genre musik tersebut merupakan musik-musik yang populer di Amerika dan kemudian berkembang secara pesat serta dikenal sampai ke seluruh dunia. Tapi hanya beberapa genre musik tertentu yang berpengaruh dan dipopulerkan di Indonesia seperti Rock, Blues, POP, Reggae, Hip Hop, Blues dan Jazz. Genre musik tersebut adalah genre atau jenis musik yang masuk ke Indonesia karena pengaruh dari budaya barat. Orang-orang barat yang datang ke Indonesia membawa budaya mereka dan mempopulerkan genre-genre musik tersebut hingga dapat diterima di masyarakat Indonesia (Augustin, 2015).

Salah satu media dimana seni musik dapat dipertunjukkan adalah dalam festival musik. Menurut W.J.S. Purwadarwinta, kata festival sendiri mempunyai arti sebuah pekan atau hari gembira dalam rangka peringatan suatu peristiwa penting dan bersejarah, sehingga arti ini menunjukan bahwa festival adalah pesta rakyat. Sedangkan menurut KBBI festival dapat didefinisikan sebagai suku kata yang bermakna 
pesta, arti ini memberikan pemahaman bahwa festival ialah perayaan besar yang di lakukan untuk memperingati sesuatu kejadian yang bersejarah. (IndonesiaStudent, 2017) Dari kedua definisi diatas, dapat kita simpulkan bahwa festival merupakan sebuah acara yang dilangsungkan bisa dalam satu hari atau satu pekan yang ditujukan sebagai sebuah selebrasi atau perayaan atas suatu hal yang menggembirakan.

Dari situ, kita bisa masuk kedalam apakah festival musik itu sebenarnya dan bagaimana masyarakat Indonesia menyikai fenomena festival musik ini sendiri. Festival musik masuk kedalam seni pertunjukkan dimana adanya suatu seni pertunjukkan yang diadakan di berbagai tempat dengan membawakan alunan-alunan musik di dalam acara tersebut. Festival musik bukanlah hal yang baru, namun popularitas acara seperti Bonnaroo (Manchester, 2002) dan Glastonbury (Inggris, 1970) telah tumbuh lebih besar dalam beberapa tahun terakhir. Sebagai sebuah alternatif, semangat perlawanan pada festival musik telah berkembang menjadi sesuatu yang jamak dan mencakup segala acara. Meskipun Woodstock (pertama kali diadakan tahun 1969) mungkin paling banyak dibicarakan sebagai festival musik paling bersejarah, tetapi ternyata Woodstock bukanlah festival musik yang pertama dari jenisnya (Prambanan Jazz, 2018, para. 3).

Coachella, Summer Sonic, atau Reading and Leeds mungkin menjadi salah satu festival musik yang cukup diminati masyarakat Indonesia. Pesta musik internasional ini memang sudah tidak diragukan lagi kemeriahannya. Sebagai seorang penikmat musik, menyaksikan penampilan musisi favorit tentu menjadi pengalaman menarik yang tak terlupakan. Bahkan, banyak yang rela datang jauhjauh demi menikmati kemeriahan pesta musik tahunan ini. Untuk orang-orang yang belum bisa mengunjungi festival musik di luar negeri seperti di atas, sebetulnya festival musik yang ada di Indonesia pun tidak kalah dalam hal kualitas (Rosyid, 2018, para. 1). Festival-festival musik di atas merupakan acara yang secara umum di peringkat atas atau dengan kata lain tergolong digemari oleh mayoritas publik.

Dimana seperti dilansir oleh idntimes.com, perkembangan festival musik di Indonesia cukup baik beberapa tahun belakangan ini. Konsep festival yang unik, serta animo kaum milenial untuk datang ke festival musik, membuat artis papan atas dunia tertarik untuk manggung di Indonesia. (Rosyid, 2018, para. 2) Festival-festival music seperti JavaJazz, Lalala, WTF, Soundrenaline, dan jajaran festiva local dengan bintang tamu artis luar negeri pun menjadi salah satu contoh festival music yang tiap tahunnya senantiasa dinantikan oleh para penggemarnya.

Pada tahun 2017 murid-murid SMA Teruna Muda Cibubur pun sudah mengikuti ujian musik yang diadakan oleh guru-guru mereka di sekolah dengan format sebuah festival musik dimana mereka harus memilih salah satu di antara tiga jenis alat musik yang bisa mereka bawakan saat ujian nanti, yaitu gitar, keyboard, dan drum. Melihat fenomena festival musik yang sedang menjamur di kalangan masyarakat dan kejadian nyata yang terjadi di SMA Teruna Muda Cibubur, perancang merasa bahwa ada benang merah yang bisa disambungkan. Dari situlah peranang ingin 
membawakan konsep baru dalam ujian musik yang setiap tahunnya dilakukan oleh para murid di SMA Teruna Muda Cibubur yaitu dalam bentuk festival musik atau konser musik. Dengan tema "Musikal", pada saat ujian, para murid akan memainkan beberapa lagu daerah Indonesia dengan salah alat musik yang disediakan didepan siswa-siswi yang lain, dan didukung oleh panggung yang didekorasi dengan kerajinan tangan mereka sendiri. Penampilan mereka nantinya akan dinilai oleh para guru yang menyaksikan acara ini.

Selain itu ajang kreativitas yang membawa para murid SMA Teruna Muda Cibubur untuk ikut membawakan beberapa alunan musik/aransmen yang anak-anak buat dan ditampilkan saat festival musik yang bertema musikal, yang bertempat di sekolah itu sendiri, selain itu juga untuk meningkatkan kreatifitas dan menanam jiwa seni budaya, seperti wadah yang disediakan di sekolah dengan ekstrakurikuler seni musik, sehingga bisa menjadi bekal saat anak- anak tumbuh di era globalisasi. Konsep perencanaan festival musik ini, akan berlangsung di SMA Teruna Muda Cibubur, jadi hal tersebut mendorong perancang karya untuk membuat konsep untuk acara festival musik “musikal”, musikal yang dimaksud oleh tema yang perancang karya buat adalah musikalitas dari anakanak SMA Teruna Muda ini. Perancang karya akan bertindak selaku perancang konsep acara, untuk menciptakan sebuah konsep melalui tugas akhir yaitu sebuah non skripsi yang berjudul "Konsep Perencanaan Festival Musik di SMA Teruna Muda Cibubur".

\section{METODE PENELITIAN}

Berikut adalah penjelasan pembagian perencanaan konsep event dari perancang karya sesuai dengan teori perencanaan event yang dipakai perancang karya menjadikan buku Manajemen Event karya dari Any Noor sebagai dasar dalam perencanaan konsep, berikut adalah penjelasan pembagian perencanaan konsep event sesuai dengan teori management event yang dipakai. Menciptakan dan menghasilkan sebuah karya agar dapat menumbuhkan kembali jiwa generasi muda yang cinta akan seni budaya tepatnya seni musik, untuk mengasah kreatifitas mereka untuk siap bersaing dalam industri musik/ kreativitas di era globalisasi.

Setiap langkah awal dalam proses perencanaan event dimulai dengan menetapkan sebuah tujuan yang dapat diterima dengan jelas oleh setiap anggota tim yang akan terlibat. Kejelasan tujuan event yang dimunculkan pada proses perencanaan akan membawa setiap anggota tim pada tujuan dan arah yang sama dalam melaksanakan event tersebut. Dalam hal ini, penetapan tujuan yang dilakukan oleh perancang karya mencakup latar belakang ide, visi dan misi serta penetapan kriteria (target audience) dari acara yang akan diselenggarakan.

Dalam mengelola suatu kegiatan tentunya diperlukan sebuah strategi. Strategi yang tepat hanya dapat dilakukan apabila penyelenggara event mengetahui dengan pasti apa tujuan dari diselenggarakannya event tersebut.

Tujuan merupakan langkah awal dalam setiap perencanaan sebuah event. Tujuan diselenggarakannya suatu event dapat berupa 
pembelajaran, bertukar pikiran, sosialisasi, peringatan, hiburan, mempromosikan produk baru perusahaan atau meningkatkan pendapatan perusahaan dan sebagainya. (Noor, 2013, p. 132)..

\section{HASIL DAN PEMBAHASAN}

Tujuan penulisan konsep event festival Musik "Musikal" dari para murid SMA Teruna Muda Cibubur adalah untuk menjadi wadah para peminat seni khususnya seni musik serta mengangkat kembali minat para anak muda akan musik musik lokal yang dikemas dalam bentuk festival musik. Tahap rencana awal adalah melakukan riset dan penyelenggaraan event dimulai dengan dua tahap, yaitu: a. Pencarian Informasi, dalam tahap ini yang dicari adalah informasi tentang competitor, masalah yang sekiranya menjadi kendala dalam acara yang akan dibuat, apa yang menjadi persamaan atau perbedaan dengan acara-acara sebelumnya serta siapa yang akan terlibat dalam proses penyelenggaraan dan saat event berlangsung. b. Mengumpulkan Infomasi, dalam tahap ini perancang karya mengumpulkan informasi yang telah dicari menjadi satu, seperti tersedianya waktu dan tempat untuk pelaksanaan event dan penetapan staf atau tenaga kerja yang sesuai dengan keterampilan dan kemampuan yang dibutuhkan event.

Dalam tahap ini, perancang karya mulai mencari dan mengumpulkan siapa saja calon-calon yang terlibat dalam acara, mengidentifikasi partisipan, dan memastikan pihak yang terlibat dalam event seperti staf atau kru yang sesuai dengan bidangnya. Rencana Detil Setelah semua informasi dalam rencana awal telat didapatkan, tahap selanjutnya adalah menuangkan rencana kedalam perencanaan yang lebih detil dan kemudian rencana tersebut dilakukan oleh pihak yang sudah ahli dalam bidangnya. Rencana detil terbagi menjadi tiga bagian, yaitu: a. Rencana keuangan, dalam tahap ini akan membuat rencana detil tentang keuangan seperti anggaran, pemasukan, pengeluaran, sponsor, hingga pembuatan laporan keuangan event. b. Rencana operasional, dalam tahap ini akan menyusun rencana operiasional seluruh kebutuhan penyelenggaraan event secara detil seperti staf dan tim yang akan terlibat, jadwal pekerjaan, logistik, peralatan, dan lainnya. c. Rencana pemasaran, dalam tahap ini adalah tahap dimana mempromosikan informasi event agar bisa sampai pada sasaran yang tepat.

Dalam tahap ini, perancang karya akan membuat anggaran biaya yang akan menjadi pemasukan dan pengeluaran dalam kegiatan acara, preview proposal untuk calon sponsor, media partner dan donatur yang akan mendukung acara tersebut. Setelah itu dilanjutkan dengan rencana operasional, yaitu membuat tim kerja serta menjelaskan tugas dan tanggung jawab yang akan dikerjakan, membuat kebutuhan desain promosi seperti desain logo, poster, undangan, cover proposal, dan lainnya. Kemudian dilanjutkan dengan desain layout venue serta rundown acara dan timeline. Untuk tahap rencana pemasaran, perancang karya memikirkan bagaimana mempromosikan acara dengan menggunakan materi promosi yang sudah dibuat.

Visi, acara ini bermaksud untuk menjadi wadah kepada para anak untuk membangun ketertarikan mereka terhadap seni musik serta mengajak mereka untuk mengekspresikan diri mereka melalui seni, 
serta untuk membangkitkan jiwa musikalitas mereka lewat sebuah acara yang juga mereka minati. Misi. Perancang karya membuat konsep event festival musik "Musikal guna membangun ketertarikan para anak untuk menjadikan seni sebagai sarana mengekspresikan diri serta memberikan wadah kepada anak-anak untuk mengekspresikan diri melalui seni yang akan dikemas menjadi sebuah konsep event Festival Musik "Musikal"

Rencana detil kedua merupakan rencana operasional yang dimana bidang operational event harus detil dalam menyusun rencana operasional seluruh kebutuhan yang berhubungan dalam penyelenggaraan event. Mulai dari kebutuhan akan sumber daya, tim/kru, logistik, peralatan, timeline, rundown, jadwal pekerjaan, dan lainnya. Rencana operasional dapat diklasifikasikan ke dalam dua jenis rencana, yaitu rencana rutin (standing plans) dan rencana incidental (single-use plans). Standing plans adalah rencana yang digunakan lebih dari sekali. Standing plans antara lain meliputi kebijakan, aturan dan prosedur. Sedangkan singleuse plans merupakan rencana yang hanya dipakai sekali, misalnya proyek. (Wijayanto, 2012, p. 80)

Elemen kritis dari perencanaan organisasional yang efektif adalah pengembangan dan implementasi rencana operasional. Rencana operasional berasal dari rencana taktis dan ditujukan untuk mencapai tujuan operasional. Oleh karena itu, rencana operasional cenderung berfokus sempit, memiliki horizon waktu yang relatif singkat, dan melibatkan manajer tingkat rendah. (Griffin, 2004, p. 207). Salah satu prosedur yang terdapat di dalam rencana operasional adalah dengan membuat program kerja, yaitu langkahlangkah strategis yang akan dijalankan dan menentukan siapa melakukan apa, maka karena itu terbentukah sebuah struktur organisasi dalam sebuah acara. Struktur Organisasi Event, Banyak hal yang perlu dikerjakan di dalam sebuah acara sehingga harus melibatkan banyak orang, dan masing-masing orang akan bekerja di divisinya masing-masing yang tentunya berkesinambungan dengan divisi lainnya. Agar berjalannya sebuah acara dengan baik dan tertata, teciptalah sebuah struktur organisasi. "Struktur Organisasi dapat diartikan sebagai susunan dan hubungan antara bagian dan posisi dalam perusahaan. Struktur organisasi menjelaskan pembagian aktivitas kerja, serta memperhatikan hubungan fungsi dan aktivitas sampai batas-batas tertentu. Selain itu, struktur organisasi memperlihatkan tingkat spesialisasi aktivitas tersebut. Struktur organisasi juga menjelaskan hirarki dan susunan kewenangan, serta hubungan pelaporan (siapa melapor pada siapa). Dengan adanya struktur organisasi, maka stabilitas dan komunitas organisasi bisa tetap bertahan.” (Umar, 2004, p. 65).

Berikut adalah struktur organisasi pada konsep Festival Musik "Musikal”:

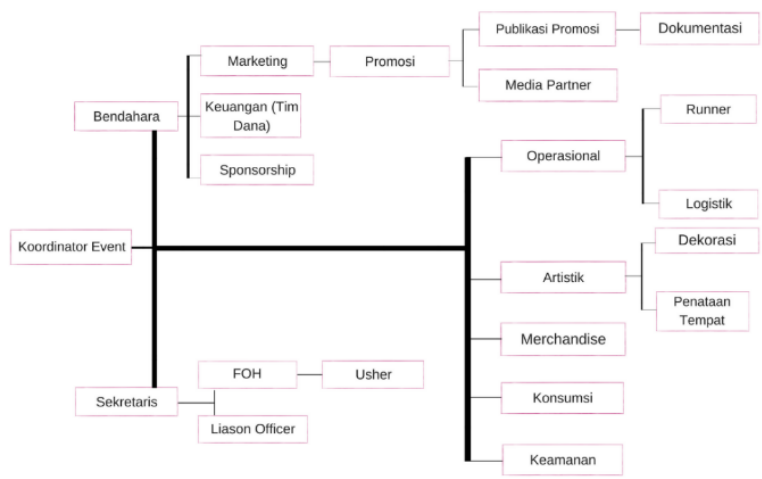

Gambar 1. Struktur Organisasi "Musikal", sumber hasil olah data perancang karya, 2019 
Sebelumnya pada tahap rencana detil bagian operasional yang telah direncanakan sedemikian rupa, diharapkan dapat berjalan sesuai dengan rencana, sesuai seperti yang dibayangkan.

Dalam tahap ini event koordinator harus mampu mengontrol dengan semua divisi melalui ketua tim dari bidangnya masing-masing (person in charge), dan ketua tim tersebut juga mampu mengontrol dengan seksama dan teliti kepada divisi mereka masing-masing agar acara dapat berjalan lancar sesuai dengan rencana.

\section{SIMPULAN}

1. Tahap terakhir dalam proses perencanaan yang tidak kalah penting adalah legalitas, yang dalam artian acara sudah

2. mendapat persetujuan dari pihak-pihak yang berwenang sehingga acara yang diselenggarakan dapat dilihat kejelasannya, status keanggotaan dalam organisasi atau kepanitiaan tersebut, perizinan agar acara dapat terselenggarakan dengan baik dan kontrak serta kerjasama dengan pihak lain yang terkait dengan acara tersebut.

3. Saat acara telah selesai, akan ada tahap evaluasi, yang dimana perancang karya akan mengumpulkan seluruh laporan dari masing-masing divisi, menyimpulkan kelebihan dan kekurangan serta apa yang perlu diperbaiki jika suatu saat nanti perancang karya dan tim akan mengadakan acara seperti festival musik lagi, perancang bisa mendapatkan feedback dari para pengunjung, dan lain-lain.

\section{DAFTAR PUSTAKA}

Augustin, C. (2015). Analisis Pengaruh Core Service Quality dan Peripheral Service Quality terhadap
Perceived Value, Customer Satisfaction, dan Repurchase Intention (Suatu Studi Pada Pengunjung Java Jazz Festival 2015)". Diakses dari website:http://kc.umn.ac.id/341/1/BAB\%20I.pdf\. Diakses pada tanggal 27 Maret 2019.

Fadillah, S.F. (2019). Pengertian Seni Beserta Fungsi, Konsep dan Cabang-Cabang Seni. Diakses dari https://www.nesabamedia.com/pengertian-seni/. Diakses tanggal 27 Maret 2019.

Griffin, R. W. (2004). Manajemen edisi ketujuh (terjemahan). Jakarta: Erlangga.

Indonesia Student. (2017). 4 Pengertian festival Menurut Para Ahli, Jenis, dan Contohnya Lengkap. Diakses darihttps://www.indonesiastudents.com/pengertia n-festival-menurut-para-ahli-jenis-dancontohnya/.Diakses pada tanggal 27 Maret 2019.

Manroe, M. (2018). Pengertian Seni : Definisi, Fungsi, Tujuan, Dan Macam-Macam Seni. Diakses dari https://www.maxmanroe.com/vid/umum/pengerti an-seni.html. Diakses pada tanggal 25 maret 2019.

Noor, A. (2009). Manajemen Event. Bandung: Alfabeta. (Mulyana, D. , 2007)

Prambanan Jazz, (2018) Prambanan Jazz. Diakses dari website https://www.prambananjazz.com/sejarahfestivalmusik/ Diakses Pada tanggal 27 Maret 2019.

Rosyid, A.U. (2018). 7 Festival Musik Indonesia Yang Nggak Kalah Dengan Luar Negeri. Diperoleh dari https://www.idntimes.com/hype/entertainment/ah maduzlif/7festivalmusikindonesiayanggakkalaeng andi-luar-negeri-c1c2/full

Umar, H. (2004). Business an introduction. Jakarta: PT Gramedia Pustaka Utama.

Wijayanto, D. (2012). Pengantar Manajemen. Jakarta: Gramedia Pustaka Utama 